\title{
Thermal Transformation of Fired Clay Ceramics by Dilatometric Analysis
}

\author{
L. Beddiar ${ }^{a, b}$, F. Sahnoune ${ }^{b, c, *}$, M. Heraiz ${ }^{b}$ And D. Redaoui ${ }^{b}$ \\ ${ }^{a}$ Department of Science of Materials, University Mohamed Khaiddar Beskra, Algeria \\ ${ }^{b}$ Physics Department, Faculty of Science, University Mohamed Boudiaf of M'sila, 28000 M'sila, Algeria \\ ${ }^{c}$ Research Unit on Emerging Materials (RUEM), Ferhat Abbas of Setif 01, 19000 Setif, Algeria \\ In the present study the mechanism and kinetic parameters of allotropic transformation $(\alpha \rightarrow \beta)$ of the quartz \\ of Algerian clay from Al-maathed was studied by dilatometric analysis technique. The activation energies measured \\ by both isothermal (Johnson-Mehl-Avrami theory using Ligero method) and non-isothermal (Kissinger methods) \\ treatments were 980 and $1050 \mathrm{~kJ} \mathrm{~mol}^{-1}$, respectively. The growth morphology parameters $n$ (Avrami parameter) \\ which indicates the crystallization mode were found to be almost equal to 1.5, using non-isothermal treatments, \\ and equal to 1.4 using isothermal (Ligero method). The numerical factor which depends on the dimensionality \\ of crystal growth $m$ obtained by Matusita et al. equation was 1.50. Analysis of the results shows that the bulk \\ nucleation is the dominant mechanism in $\beta$-quartz crystallization and the three-dimensional growth of $\beta$-quartz \\ crystals with polyhedron-like morphology occurs, controlled by diffusion from a constant number of nuclei.
}

DOI: 10.12693/APhysPolA.134.86

PACS/topics: ceramics, thermal analysis, powders

\section{Introduction}

Clays and clay minerals are very important raw materials in process industries, agriculture, engineering, construction, geology, environmental, and for other miscellaneous applications. They have been widely used as the main raw materials in the fabrication of diversified ceramic products for construction materials such as bricks and tiles due to their specific properties before and after firing $[1,2]$.

Clays are formed by many processes such as hydrothermal, weathering, sedimenting, etc. They have generally buff, gray, brown, or rusty colors due to the content of clay minerals and due to iron oxides/hydroxides. The clay raw material which was used in this project was obtained from the brickyard area of Al-maathed in the central area of Algeria. This Algerian clay was chosen for its wide applications in the pottery and brick making industries.

The experiments of this study were conducted similar to the traditional practices of potters, to understand the thermal transformation of fired clay ceramics by dilatometric analysis of these materials. Therefore the clays were manually shaped and pressed into a mould, then dried and after that fired.

Densification behavior of clays fired at various temperatures under different heating rates was evaluated. It is expected that the present investigation will collect the knowledge on optimization of the clay ceramics processing.

*corresponding author; e-mail: sahnounefoudil@yahoo.com
This study is devoted to the investigation of the thermal transformation of Algerian clay under different firing conditions in order to obtain the nonisothermal and isothermal activation energies of crystallized $\beta$-quartz, and the values of the growth morphology parameters $n$ and $m$.

\section{Materials and experimental procedure}

Clay materials were taken from a brick-manufacturing factory located at M'sila site in Algeria. The chemical composition of this mineral was determined by X-ray fluorescence (XRF), as shown in Table I.

Chemical composition (wt.\%) of clay mineral (calcined at $T=700{ }^{\circ} \mathrm{C}$ ).

\begin{tabular}{c|c|c|c|c|c|c|c}
\hline \hline $\mathrm{Al}_{2} \mathrm{O}_{3}$ & $\mathrm{SiO}_{2}$ & $\mathrm{CaO}$ & $\mathrm{MgO}$ & $\mathrm{SO}_{3}$ & $\mathrm{~K}_{2} \mathrm{O}$ & $\mathrm{Na}_{2} \mathrm{O}$ & $\mathrm{Fe}_{2} \mathrm{O}_{3}$ \\
\hline 15.27 & 68.18 & 6.86 & 3.30 & 1.22 & 1.77 & 0.69 & 2.69
\end{tabular}

Clay was fired in a furnace at 200, 600, 950 and $1050^{\circ} \mathrm{C}$ for one hour with heating rate of $10^{\circ} \mathrm{Cmin}^{-1}$. $\mathrm{X}$-ray diffraction (XRD) was used to identify the phases formed in the heated clay powders. XRD measurements were carried out on powder using a focalization Bragg-Brentano X-ray diffractometer, with $\mathrm{Cu}-\mathrm{K}_{\alpha}$ radiation with the wavelength of $1.5418 \AA$ and operating at $40 \mathrm{kV}$ and $40 \mathrm{~mA}$. The diffraction angle range was $15^{\circ} \leq 2 \theta \leq 40^{\circ}$.

The dilatometry measurements were carried out on the clay with a dilatometer (NETZSCH DIL 402C). The samples were fired from room temperature to $1000^{\circ} \mathrm{C}$, at heating rates of $4,8,10,12,16$ and $20^{\circ} \mathrm{Cmin}^{-1}$.

In the case of the non-isothermal method the activation energy $E_{\mathrm{A}}$ of crystallization is calculated using Ozawa [3, 4], Boswell [5] and Kissinger [6] methods. The 
theoretical basis for the dilatometry results is provided under the isothermal condition using the Johnson-MehlAvrami (JMA) theory. This method describes with the time, $t$, the evolution of the crystallization fraction, $x$, during a phase transformation:

$$
x=1-\exp \left[(-k t)^{n}\right] .
$$

Here $x$ is the volume fraction crystallized after time $t$. It was obtained from the dilatometry results as follows:

$$
x=\frac{A_{\mathrm{T}}}{A_{0}},
$$

where $A_{\mathrm{T}}$ is the area of the peak in the dilatometer curve at temperature $T$ and $A_{0}$ is the total area of the peak.

$$
k=k_{0} \exp \left(-\frac{E_{\mathrm{A}}}{R T}\right) .
$$

Here $k_{0}$ is the frequency factor, $T$ is the temperature in Kelvin, $E_{\mathrm{A}}$ is the activation energy and $R$ is the ideal gas constant.

Through the non-isothermal techniques Ligero et al. $[7,8]$ suggested a mathematical method in which the activation energy can be obtained from the slope of the Eq. (4) if we select the same value of $x$ in every experiment with the useful heating rate. There must be a linear relationship between $\ln (\mathrm{d} x / \mathrm{d} t)$ and $1 / T$, the slope of which provides the activation energy.

$$
\begin{gathered}
\ln \left(\frac{\mathrm{d} x}{\mathrm{~d} t}\right)=\ln \left(k_{0} n\right)+\frac{n-1}{n} \ln (-\ln (1-x))-\frac{E_{\mathrm{A}}}{R T}= \\
\ln \left(k_{0} f(x)\right)-\frac{E_{\mathrm{A}}}{R T} .
\end{gathered}
$$

Then, it is probable to calculate the value of crystallized fraction $x$ at various heating rates. Hence, the Avrami parameter $n$ was calculated from the plot $\ln \left(k_{0} f(x)\right)$ vs $1 / T$. We can select many pairs of $x_{1}$ and $x_{2}$ that satisfy the condition $\ln \left(k_{0} f\left(x_{1}\right)\right)=\ln \left(k_{0} f\left(x_{2}\right)\right)$.

$$
n=\frac{\ln \left(\ln \left(1-x_{2}\right) / \ln \left(1-x_{1}\right)\right)}{\ln \left(\left(1-x_{2}\right) \ln \left(1-x_{2}\right) /\left(1-x_{1}\right) \ln \left(1-x_{1}\right)\right)} .
$$

\section{Results and discussion}

Figure 1 shows the typical shrinkage curves for clay powder at different heating rates (Fig. 1a) and first derivative of shrinkage curves for transformation of quartz from phase $\alpha$ to phase $\beta$ (Fig. 1b).

Figure 1a shows a linear shrinkage of the clay heated at different heating rates $2.5^{\circ} \mathrm{Cmin}^{-1}$ to $10^{\circ} \mathrm{Cmin}^{-1}$. Relative expansions at temperatures lower than $100^{\circ} \mathrm{C}$ are due to the evaporation of the adsorbed water. Relative shrinkage which starts at $100^{\circ} \mathrm{C}$ and ends at $200^{\circ} \mathrm{C}$ is due to the dehydration of the clay powder [9].

The second expansion appearing at about $578^{\circ} \mathrm{C}$ results in an allotropic transformation of quartz $(\alpha \rightarrow \beta)$. This transformation is very fast and causes a sudden increase in volume ( $1.3 \%$ for the quartzite) corresponding to a linear elongation of $0.45 \%[9,10]$.

The third relative shrinkage between $860^{\circ} \mathrm{C}$ and $940^{\circ} \mathrm{C}$ corresponds to sintering steps. Figure $1 \mathrm{~b}$ depicts the first derivative of shrinkage curves for transformation of
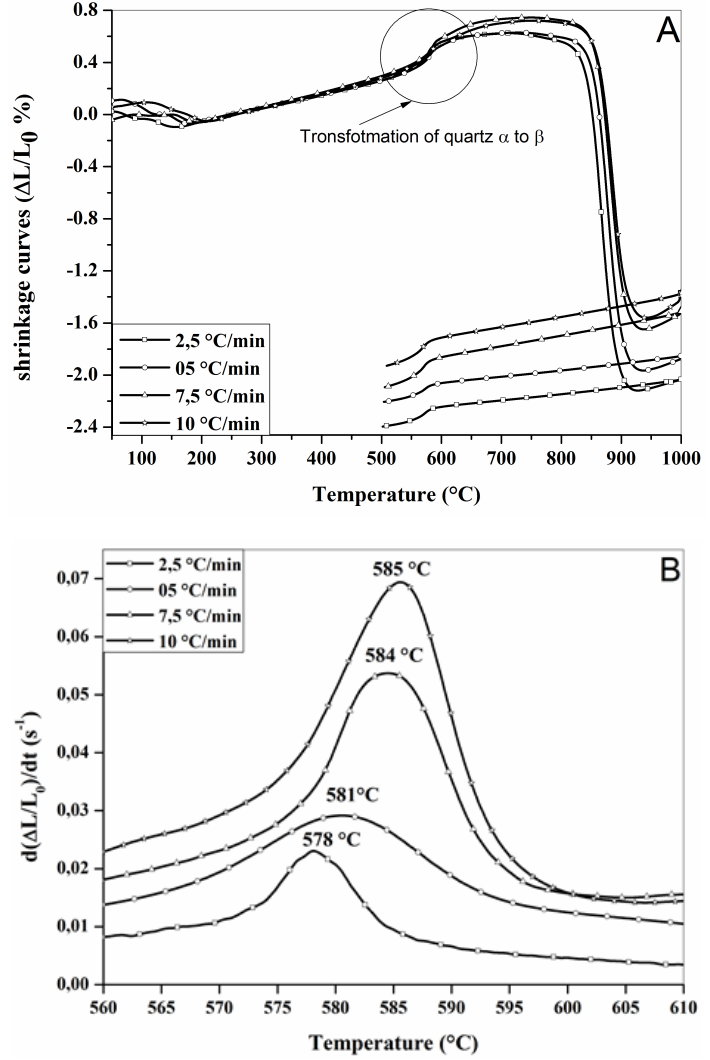

Fig. 1. Shrinkage curves of clay powder at different heating rates (a) and the first derivative of shrinkage curves for transformation of quartz $\alpha \rightarrow \beta$ (b).

quartz $(\alpha \rightarrow \beta)$. The temperature of the maximum of the exothermic peak, $T_{\mathrm{p}}$, shifts to a higher temperature as the heating rate increases from 2.5 to $10^{\circ} \mathrm{Cmin}^{-1}$. The calculated energy of phase transformation of quartz $(\alpha \rightarrow \beta)$ obtained by various methods is shown in Fig. 2 and its values are shown in Table II.

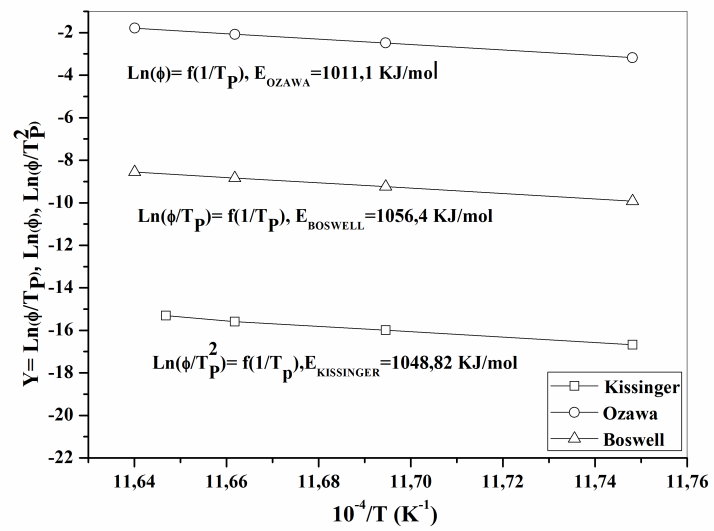

Fig. 2. Plots of $Y$ versus $10^{4} / T_{\mathrm{p}}$ for phase transformation of quartz $(\alpha \rightarrow \beta)$. 
TABLE II

Values of $E_{\mathrm{A}}$ and $R^{2}$ obtained using Kissinger,

Ozawa and Boswell methods.

\begin{tabular}{l|c|c|c}
\hline \hline \multicolumn{1}{c|}{ Method } & Kissinger & Ozawa & Boswell \\
\hline$E_{\mathrm{A}}\left[\mathrm{kJ} \mathrm{mol}^{-1}\right]$ & 1049 & 1011 & 1056 \\
\hline$R^{2}$ & 0.995 & 0.994 & 0.997
\end{tabular}

Figure 3a shows the variation of the crystallized fraction of $\beta$-quartz formation with temperature under different heating rates. The crystallized fraction $x$ was determined from the dilatometry results (Fig. 1a).
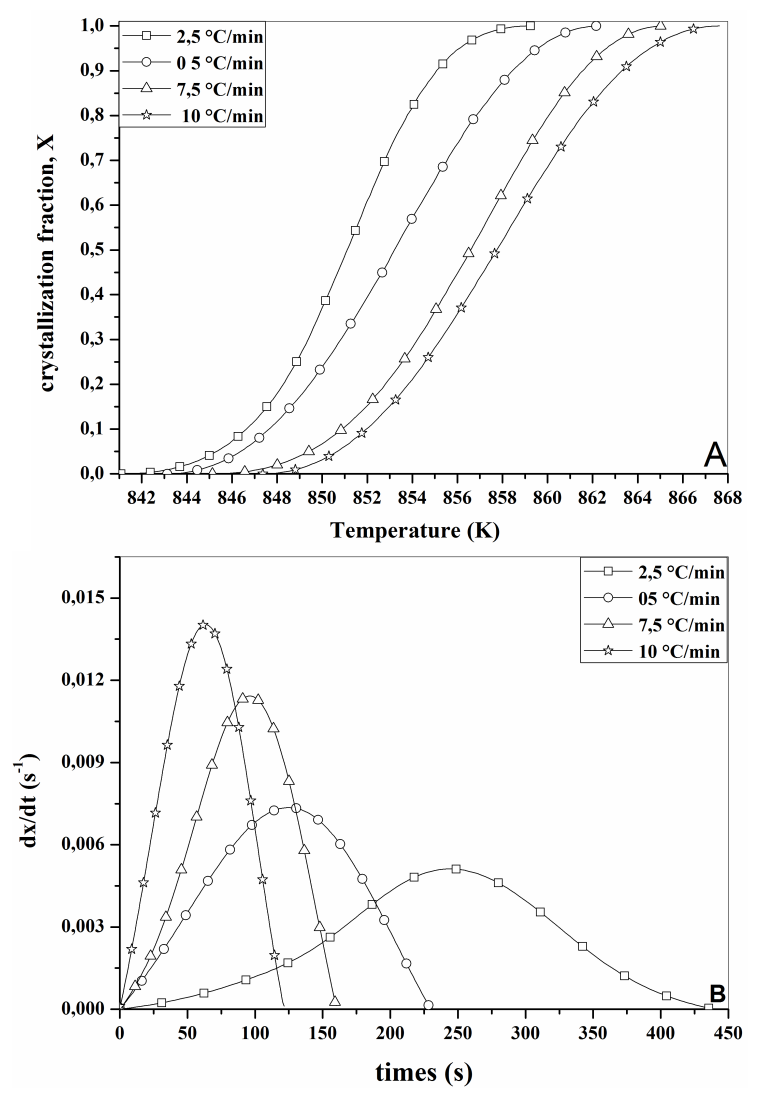

Fig. 3. Crystallized fraction (a) and the rate (b) of $\beta$ quartz growth with time, under different heating rates.

As estimated, the crystallization fraction, $x$, at a temperature $T$ differs at different heating rates and hence the curves $\mathrm{d} x / \mathrm{d} t$ versus time are also different as is shown in Fig. $3 \mathrm{~b}$, which depicts the rate of $\beta$-quartz growth with time for different heating rates.

The rate of crystallization increases with the heating rate. Figure $4 \mathrm{a}$ shows the plot of the $\ln (\mathrm{d} x / \mathrm{d} t)$ versus $1 / T$ at the same value of $x$. The values of the activation energy, $E_{\mathrm{A}}$, for different crystallized fraction, which were calculated by the average of the slopes of the lines, are listed in Table III.

The average activation energy of phase transformation of quartz $(\alpha \rightarrow \beta)$ in clay mineral is $858 \mathrm{kJmol}^{-1}$. Figure $4 \mathrm{~b}$ shows the plot of $\ln \left(k_{0} f(x)\right)$ versus $x$ for phase
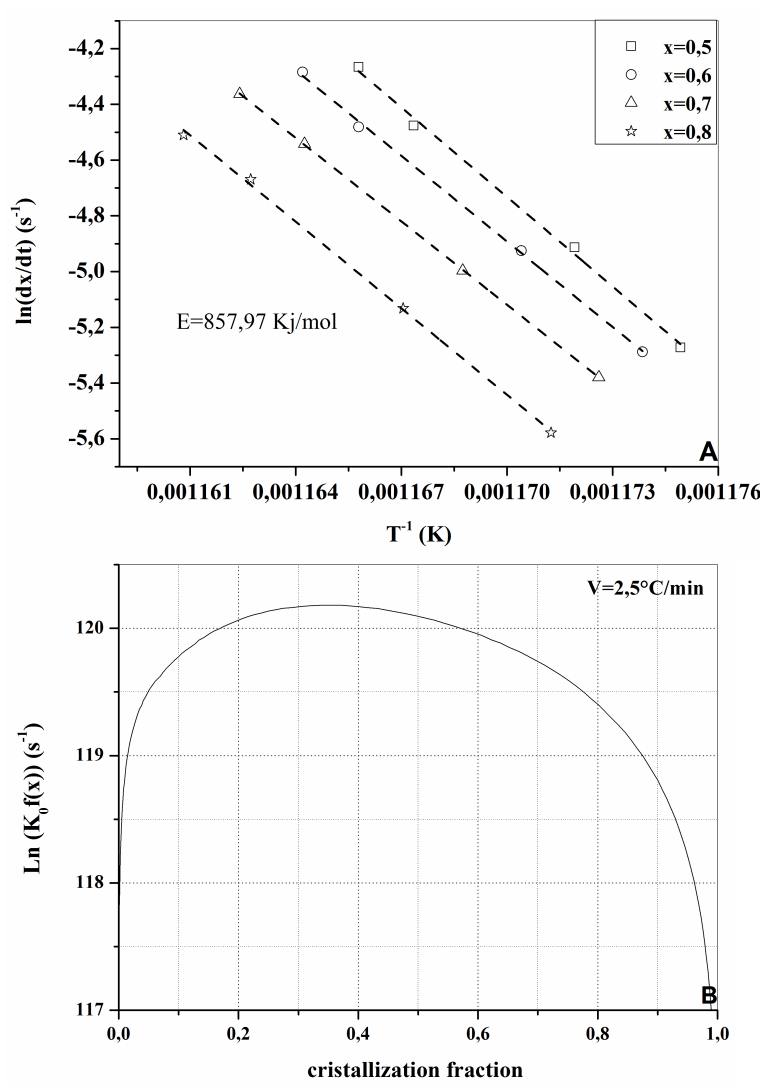

Fig. 4. Plot of $\ln (\mathrm{d} x / \mathrm{d} t)$ vs $1 / T$ for the same value of crystallized fraction $x$ (a). Plot of $\ln \left(k_{0} f(x)\right)$ vs crystallization fraction $x$ for clay powder heated at a heating rate of $2.5^{\circ} \mathrm{Cmin}^{-1}$ (b).

TABLE III

Values of the activation energy, $E_{\mathrm{A}}$, for different values of crystallized fraction.

\begin{tabular}{c|c|c}
\hline \hline Crystallized fraction & $R^{2}$ & $E_{\mathrm{A}}\left[\mathrm{kJ} \mathrm{mol}^{-1}\right]$ \\
\hline 0.3 & 0.9553 & 1001.87 \\
0.4 & 0.8480 & 1139.61 \\
0.5 & 0.995 & 890.696 \\
0.6 & 0.998 & 850.671 \\
0.7 & 0.999 & 830.180
\end{tabular}

transformation of quartz $(\alpha \rightarrow \beta)$ heated at a heating rate of $2.5^{\circ} \mathrm{C} \mathrm{min}^{-1}$. Similar curves were obtained for the other heating rates. The Avrami parameter, $n$, was determined. The average value of Avrami parameter was 1.5, thus showing that the crystallization process of $\beta$ - quartz in clay mineral should be controlled by the diffusion growth.

\section{Conclusions}

The dilatometric analysis conducted at heating rates of $2.5,5,7.5$ and $10^{\circ} \mathrm{Cmin}^{-1}$ shows an expansion around $570^{\circ} \mathrm{C}$ associated with the transformation of quartz $(\alpha \rightarrow \beta)$. The non-isothermal and isothermal activation 
energies of crystallized $\beta$-quartz for clay, calculated using Kissinger, Ozawa and Boswell methods were (1049, 1011 and $1056 \mathrm{~kJ} \mathrm{~mol}^{-1}$ ) and $858 \mathrm{~kJ} \mathrm{~mol}^{-1}$, respectively. The values of the growth morphology parameters $n=1.5$ indicate that bulk nucleation is the dominant mechanism in $\beta$-quartz crystallization.

\section{References}

[1] S. Mahmoudi, E. Srasra, F. Zargouni, Applied Clay Science 42, 125 (2008).

[2] J.M. Bhatnagar, R.K. Goel, Const. Build. Mat. 16, 113 (2002).

[3] T. Ozawa, Bulletin of the Chemical Society of Japan 38, 1881 (1965).
[4] J.H. Flynn, L.A. Wall, Journal of Research of NBS, Section A: Physics and Chemistry 70A, 487 (1966).

[5] P.G. Boswell, J. Therm. Anal. 18, 353 (1980).

[6] L. Beddiar, F. Sahnoune, M. Heraiz, D. Redaoui, Acta Phys. Pol. A 131, 566 (2017).

[7] F. Sahnoune, M. Chegaar, N. Saheb, P. Goeuriot, F. Valdivieso, Appl. Clay. Sci. 38, 304 (2008).

[8] M. Romero, J. Martín-Márquez, J.Ma. Rincón, J. Eur. Ceram. Soc. 26, 1647 (2006).

[9] C.N. Djangang, A. Elimbi, U.C. Melo, G.L. Lecomte, C. Nkoumbou, J. Soro, J.P. Bonnet, P. Blanchart, D. Njopwouo, Ceramics International 34, 1207 (2008).

[10] M. Murat, Powder Technology 10, 171 (1974). 